\title{
A COMMON COELIACO-MESENTERIC TRUNK AND VARIATIONS IN THEIR BRANCHING PATTERN- A CASE REPORT
}

Anbusudar Kalaimani ${ }^{1}$, G. Bharathi², K. Carolin Chirsty ${ }^{3}$, S.Ayyandurai ${ }^{4}$, M. Abishek ${ }^{5}$.

1. Assistant Professor, Department of Anatomy, Government Dharmapuri Medical College, Dharmapuri, Tamilnadu.

2. Professor and dean, Department of Anatomy, Government Dharmapuri Medical College, Dharmapuri, Tamilnadu.

3. First Year M.B.B.S Student, Department of Anatomy, Government Dharmapuri Medical College, Dharmapuri, Tamilnadu.

4. First Year M.B.B.S, Student, Department of Anatomy, Government Dharmapuri Medical College, Dharmapuri, Tamilnadu.

5. First Year M.B.B, Student, Department of Anatomy, Government Dharmapuri Medical College, Dharmapuri, Tamilnadu.

\author{
CORRESPONDING AUTHOR \\ Dr. Anbusudar Kalaimani, \\ Assistant Professor, Department of Anatomy, \\ Government Dharmapuri Medical College, \\ Dharmapuri, Tamilnadu. \\ Email- anbujeyanth@gmail.com
}

\section{HOW TO CITE THIS ARTICLE:}

Anbusudar Kalaimani, G. Bharathi, K. Carolin Chirsty, S.Ayyandurai, M. Abishek. "A Common CoeliacoMesenteric Trunk and Variations in their Branching Pattern- A Case Report." Journal of Evolution of Medical and Dental Sciences 2013; Vol2, Issue 23, June 10; Page: 4097-4101.

ABSTRACT: The Coeliac trunk and the Superior mesenteric artery are ventral branches of abdominal aorta. Sometimes these two arteries arise from the abdominal aorta in a common trunk. Many literatures are available explaining this type of variation. But this report describes not only the common coeliaco-mesenteric trunk but also a rare variation in their branching. Knowledge about the vascular variations is essential for the clinicians for therapeutic and diagnostic procedures of many abdominal diseases.

KEY WORDS: Common coeliaco-mesenteric trunk, Dorsal pancreatic artery, Common ileo-right colic branch, Inferior phrenic artery.

INTRODUCTION: The abdominal aorta has anterior, lateral and posterior branches as it passes through the abdominal cavity. The three anterior branches supply the gastrointestinal viscera: the celiac trunk, the superior mesenteric artery and the inferior mesenteric arteries.

The celiac trunk is the anterior branch of the abdominal aorta supplying the foregut. It arises from the abdominal aorta immediately below the aortic hiatus of the diaphragm, anterior to the upper part of vertebra L1. It immediately divides into the left gastric, splenic and common hepatic arteries.

The superior mesenteric artery is the anterior branch of abdominal aorta supplying the midgut. It arises from the abdominal aorta immediately below the celiac artery, anterior to the lower part of vertebra L1. After giving of its first branch the inferior pancreatico-duodenal artery the superior mesenteric artery gives off jejuna and ileal arteries on its left side. Branching from the 
right side of the main trunk of the superior mesenteric artery are three vessels- the middle colic, right colic and ileocolic arteries - which supply the terminal ileum, caecum, ascending colon and right two thirds of transverse colon.

The inferior pancreatico-duodenal artery is the first branch of the superior mesenteric artery. It divides immediately into anterior and posterior branches, which ascend on the corresponding sides of the head of pancreas.

Distal to the inferior pancreatico-duodenal artery, the superior mesenteric artery gives off numerous branches. Arising on the left is the large number of jejunal and ileal arteries supplying the jejunum and most of the ileum. These branches leave the main trunk of the artery, pass between the two layers of mesentery, and form anastomosing arches or arcades as they pass outward to supply the small intestine.

The middle colic artery is the first of the three branches from the right side of the main trunk of the superior mesenteric artery. Arising as the superior mesenteric artery emerges from beneath the pancreas; the middle colic artery enters the transverse mesocolon and divides into right and left branches. The right branch anastomoses with the right colic artery while the left branch anastomoses with left colic artery, which is a branch of the inferior mesenteric artery. Continuing distally along the main trunk of the superior mesenteric artery, the right colic artery is the second of the three branches from the right side of the main trunk of the superior mesenteric artery. It is an inconstant branch,, and passes to the right in a retroperitoneal position to supply the ascending colon. Nearing the colon, it divides into descending branch which anastomoses with the ileocolic artery, and an ascending branch, which anastomoses with the middle colic artery.

The final branch arising from the right side of the superior mesenteric artery is the ileocolic artery. This passes downward and to the right toward the right iliac fossa where it divides into superior and inferior branches. The superior branch passes upward along the ascending colon to anastomose with the right colic artery. The inferior branch continues toward the ileocolic junction dividing into colic, cecal, appendicular and ileal branches ${ }^{1}$.

CASE REPORT: During routine gross anatomy dissection of abdomen of 60 year old female cadaver in department of Anatomy Govt Dharmapuri medical college, we observed multiple variations in the branches of the upper abdominal vessels. The Coeliac trunk (CT) and the Superior mesenteric artery (SMA) arose together as a Common Coeliaco-Mesenteric trunk from the abdominal aorta at the level of LI vertebra (Fig1). The trunk was about $1.5 \mathrm{~cm}$ long and divided into two as celiac trunk and superior mesenteric artery (Fig2). The stem of the coeliac trunk was about $1.25 \mathrm{~cm}$ long and gave rise to five branches (Fig3). The usual branches the left gastric artery, the common hepatic artery and the splenic artery had the normal course. The dorsal pancreatic artery arose from the coeliac trunk just anterior to the origin of common hepatic artery. This dorsal pancreatic artery coursed towards the posterior surface of the body of pancreas. The coeliac trunk at its origin itself gave rise to the left inferior phrenic artery. At the origin the left phrenic artery lie behind the splenic artery and coursed upwards to the left dome of diaphragm (Fig4).

The Superior mesenteric artery gave rise to inferior pancreatico-duodenal artery as the first branch and the middle colic artery (MCA) as the next branch as usual. The middle colic artery divided into right and left branches (Fig5). Jejunal and ileal branches came from the left side of the SMA. From the middle of the right concavity of the SMA, it gave rise to a common trunk, the 
common ileo-right colic trunk (Fig6). This common trunk divided into right colic and ileocolic branches (Fig7). The right colic artery (RCA) divided into ascending and descending branches. The ileocolic artery (ICA) also divided into ascending and descending branches. The descending branch of ileocolic anastomosed with the terminal branch of SMA as usual.

DISCUSSION: The presence of the common coeliaco-mesenteric trunk is documented in many previous studies. The coeliac trunk typically gives rise to three major branches, the left gastric artery, the hepatic and the splenic arteries; it may likewise give rise to one or both the inferior phrenic arteries or to a branch, the dorsal pancreatic artery to the pancreas ${ }^{2}$. The coeliac trunk sometimes may give rise to any of the inferior phrenic artery ${ }^{1}$. Karakose $\mathrm{M}$ et $\mathrm{al}^{3}$ reported a dorsal pancreatic artery arising from the coeliac trunk and supplied the pancreas. Satheesh Nayak $\mathrm{B}^{4}$ reported a common trunk had three arteries, the celiac trunk, the superior mesenteric artery and 2 inferior phrenic arteries as coeliaco-mesenteric-phrenic artery. The left gastric artery and the left inferior phrenic artery arising from a common trunk and it were reported by Cavdar et al5. They reported the coeliaco- mesenteric trunk also.

In Yuksel et $\mathrm{al}^{6}$ reported the inferior phrenic artery arising from the celiac trunk and an aberrant right hepatic artery arising from the superior mesenteric artery. K. Sridhar Varma et al ${ }^{7}$ reported a common celiaco-mesentric trunk which divided into hepatomesentric and gastrosplenic trunk. Mehmet Tugrul Yilmaz et al $^{8}$ reported a case of celiaco-mesenteric trunk. The celiac trunk divided into left gastric, common hepatic and splenic arteries. Rajesh B Astik et al ${ }^{9}$ reported that the celiac trunk divided into left superior suprarenal, left middle suprarenal, gastroduodenal and inferior phrenic artery with the usual branches. Biswa Bhusan Mohanty et al ${ }^{10}$ reported that the right colic artery is the most variable branch. In his report there was no right colic artery. Dr. Ashwini $\mathrm{H}$ et al ${ }^{11}$ found in their study that in $90 \%$ of cases the middle colic and in $66 \%$ the ileocolic artery arose directly from the superior mesenteric artery. The most variable artery was the right colic artery. In $46 \%$ of cases, the RCA arose as a direct branch from SMA, whereas in 10\% cases it formed a common stem with MCA and in 34\% with ICA. The RCA was absent in $10 \%$ of cases. Steward and Rankin ${ }^{12}$ identified that the RCA arose with the ileocolic in $12 \%$ of cases.

CONCLUSION: The anatomical knowledge about the vascular pattern of the abdominal vessels is more important for the gastroenterologists, laparoscopic surgeons and radiologists. Very rare variation of this case report will be useful for the clinicians to avoid complications while doing any diagnostic and operative procedures in this region.

\author{
ABBREVIATIONS: \\ AA- ABDOMONAL AORTA \\ CT-COELIAC TRUNK \\ SMA-SUPERIOR MESENTERIC ARTERY \\ SMV- SUPERIOR MESENTERIC VEIN \\ IMA- INFERIOR MESENTERIC ARTERY \\ MCA- MIDDLE COLIC ARTERY \\ RCA- RIGHT COLIC ARTERY \\ ICA- ILEOCOLIC ARTERY
}

Journal of Evolution of Medical and Dental Sciences/ Volume 2/ Issue 23/ June 10, 2013

Page 4099 


\section{CASE REPORT}

\section{LCA- LEFT COLIC ARTERY.}

\section{REFERENCES:}

1. Susan Standring, Gray's Anatomy, The Anatomical basis of clinical practice; 40th edition, (2008), page no 494,495.

2. Henry Hollinshead. W, 2nd edition, Vol. 1, Anatomy for Surgeons; 1962, page no: 446.

3. Karakose M, Peker T, Gulekon N, Yucel D, Oktem H, Numerical variation of the celiac trunk and anatomical variation in origin and course of the dorsal pancreatic artery, Saudi Med J. 2006 Aug; 27(8):1232-5.

4. Satheesh Nayak. B Msc, phd, common celiaco-mesenterico-phrenic trunk and renal vascular variations, Saudi Med J, 2006, vol 27(12).

5. Cavdar S, Gurbuz J, Zeybek A, Sethril u, Abik L, Ozdogmms O, A variation of celiac trunk. Kaibojaku Zasshi; 1998; 73; 505-508.

6. Yuksel M, Yalin A, Weinfeld AB, Concurrent anomalies of the abdominal arteries, an extremely long celiac trunk, an inferior phrenic trunk and an aberrant right hepatic artery, Kaibojaku Zasshi; 1998; 73; 497-503.

7. K.Sridhar Varma, Narendra Pmidi, Venkat R Volla, J Vasc Bras: 2009; 8(3); 271-273.

8. Mehmet Tugrul Yilmaz, Murat Tezer, Aynur Emine Cicekcibasi, Anil Didem Aydin, Ahmet Salbacak, Biomedical Research 2013; 24 (1): 150-152

9. Rajesh B. Astik, Urvi H. Dave, International journal of anatomical variations; 20114; 83-85.

10. Biswan Bhusan Mohanty, Divya Agarwal, Sunita Sethy, Prafulla Kumar Chinara, International journal of anatomical variations; (2013) 6; 26-27.

11. Dr Ashwini H, Dr K Sandhya, Dr Archana Hatti, Dr Jaishree H, Branching pattern of the colic branches of superior mesenteric artery-a cadaveric study, Int J Biol Med Res. 2013; 4(1): 3004-3006

12. Steward J.A, and Rankin, F,W. Blood supply of the large intestine: Its surgical considerations. Arch. Surg. 26:843, 1933

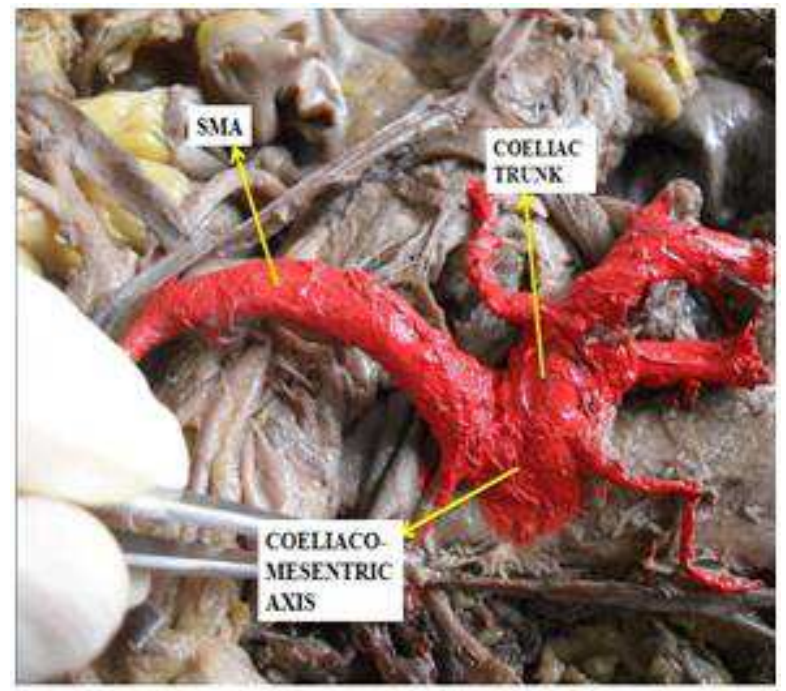

FIG 1: The common coeliaco-mesenteric trunk

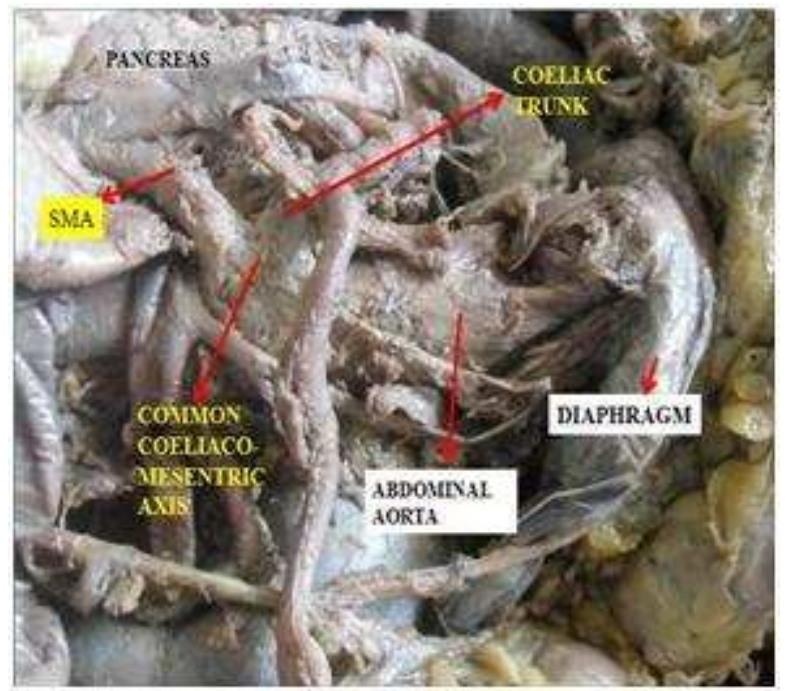

FIG 2: The CT \& SMA from common trunk 


\section{CASE REPORT}

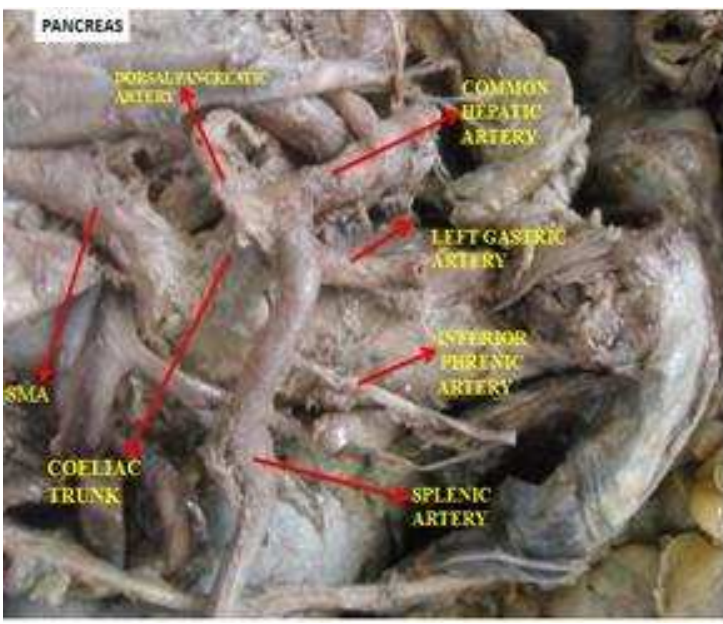

FIG 3: Coeliac trunk gives five branches

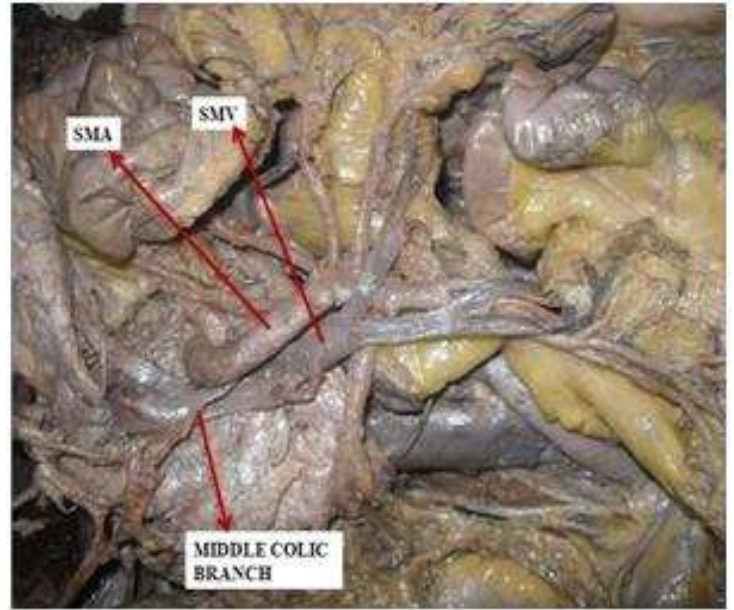

FIG 5: MCA from Superior mesenteric artery

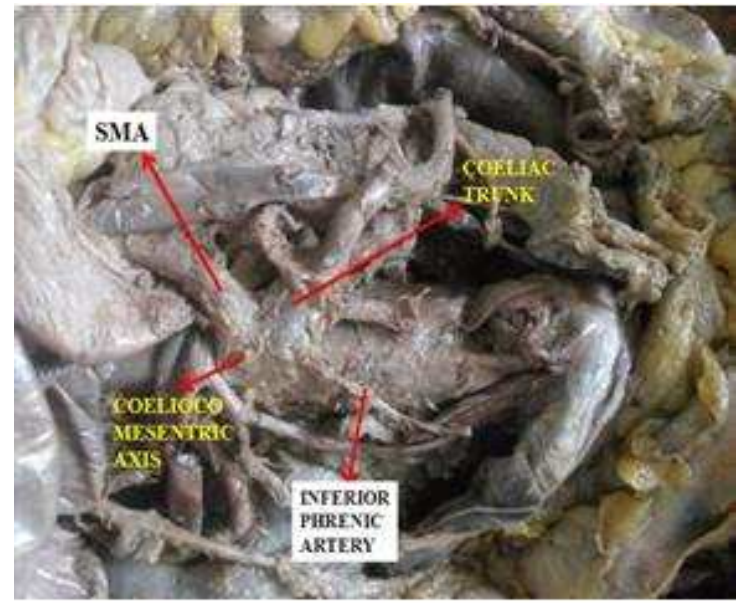

FIG 4: Left inferior phrenic artery from celiac trunk

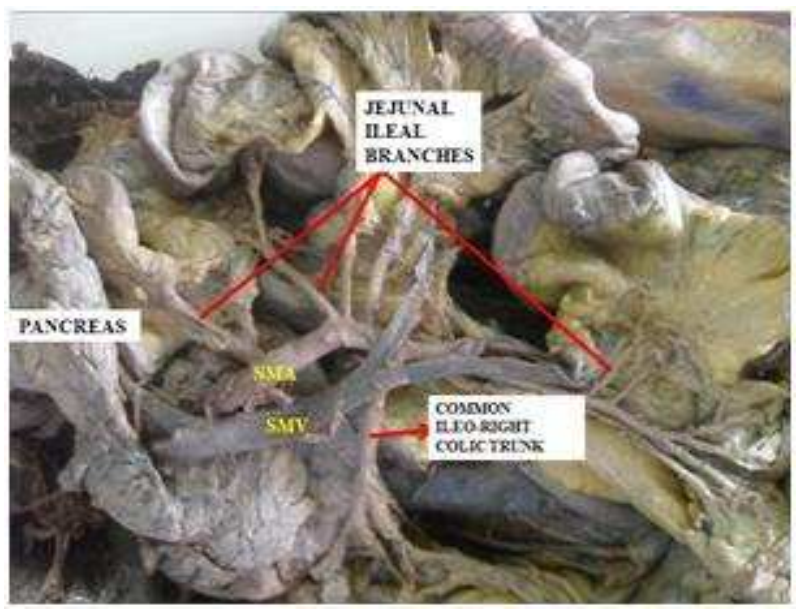

FIG 6: Common Ileo right colic trunk from SMA

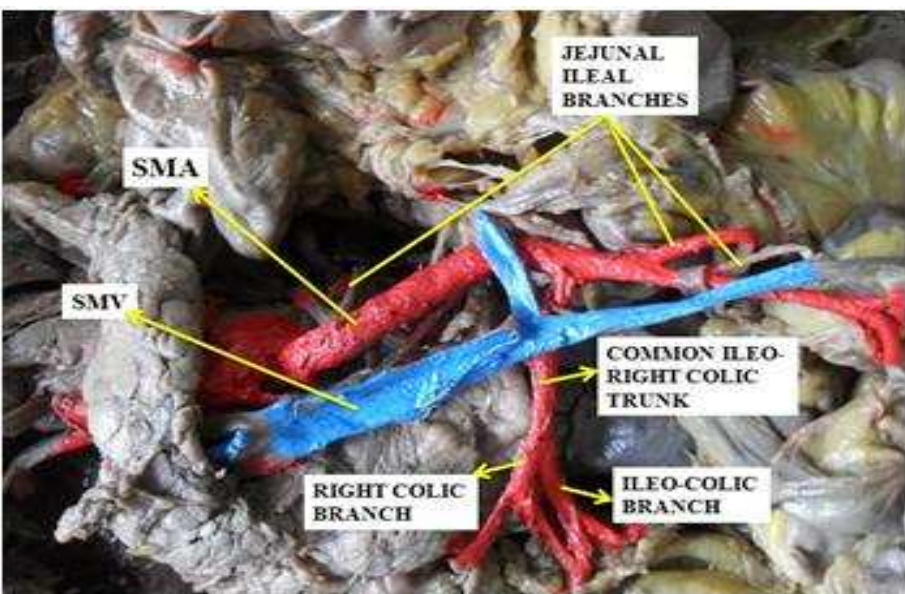

FIG 7: Common ileo right colic trunk dividing into Rightcolic and ileocolic arteries.

Journal of Evolution of Medical and Dental Sciences/ Volume 2/ Issue 23/ June 10, 2013 